www.jmscr.igmpublication.org

Impact Factor 5.84

Index Copernicus Value: 71.58

ISSN (e)-2347-176x ISSN (p) 2455-0450

crossref DOI: _https://dx.doi.org/10.18535/jmscr/v6i1.107

Journal Of Medical Science And Clinical Research

\title{
Carcinosarcoma of Uterus in a Younger Patient in a Tertiary Care Centre- A Case Report
}

\author{
Authors \\ Das Tripti ${ }^{1}$, Das Kanti Tushar $^{2}$, Mukherjee Sanghamitra ${ }^{3}$, Mahata Manisha ${ }^{4}$, \\ Barui Gopinath ${ }^{5}$
}

\begin{abstract}
Carcinosarcoma is a rare malignant tumor of the uterus with poor prognosis. We, herein, present a case of uterine carcinosarcoma in a 32-year-old woman suffering from menorrhagia and vaginal bleeding for 6 months. It was clinically suspected as carcinoma of uterus. Total hysterectomy, bilateral salpingooophorectomy and pelvic lymph node dissection were done. The histological examination revealed that the tumor comprised components of poorly differentiated carcinoma and spinle cell sarcoma presumably fibrosarcoma accompanied by immature chondromatous element. Post-operative chemotherapy was given and patient was followed up closely.

Keywords: Carcinosarcoma, Malignant Mixed Mullerian Tumour, Sarcoma,Heterologous elements.
\end{abstract}

\section{Introduction}

Carcinosarcoma of the uterus (malignant mixed mullerian tumors) is a rare occurrence, with an estimated annual incidence of $0.82 / 100,000$ worldwide, and accounts for $2-4 \%$ of uterine tumor $^{[1,2]}$. It can occur in uterus, fallopian tubes, ovaries. Carcinosarcoma is, however, highly aggressive, and is composed of epithelial and mesenchymal elements ${ }^{[3]}$.

The epithelial component of a carcinosarcoma may be any type of mullerian carcinoma: mucinous, squamous, endometrioid, high-grade serous, clear cell, undifferentiated, or mixtures of these types. $\mathrm{T}$ he endometrioid type is the most common. The stomal components may be homologous (leiomyosarcoma, stromal sarcoma, fibrosarcoma) or heterologous (chondrosarcoma, rhabdomyosarcoma,

osteosarcoma,
Our case had areas of poorly differentiated carcinoma and spindle cell sarcoma presumably fibrosarcoma with immature chondromatous element.

\section{Case Report}

A 32 year old woman admitted to hospital with complaints of menorrhagia and abdominal pain of 6 months duration along with spotting, vaginal bleeding. Physical examination revealed slight tenderness on deep palpation of lower abdomen and a sense of fullness. Endometrial biopsy was done outside. It was suspected as carcinoma of uterus.

Total abdominal hysterectomy with bilateral salpingo-oophorectomy was done and specimen was sent to the pathology department for histopathological examination. liposarcoma $)^{[4]}$. 
On gross examination of the specimen: The anatomy was grossly distorted, uterus and part of cervix measured $(16 \times 9 \times 7) \mathrm{cm}$. Some necrotic, haemorrhagic tissue were obtained from uterine cavity.

On histopathological examination, tissue from uterocervical junction and necrosed area from uterine cavity and right sided broad ligament show areas poorly differentiated carcinoma (fig. 3) and spindle cell sarcoma presumably fibrosarcoma (fig.2) with immature chondromatous element (fig.4).

Epithelial components showed poorly differentiated areas with some glandular stuctures lined by cells having pleomorphic, hyperchromatic nuclei (fig. 1).

Some foci showed haphazard admixture of highgrade poorly differentiated malignant epithelial component, having pleomorphism and at places, mesenchymal components having area of spindle cell sarcoma with immature chondromatous element (fig.5)

Finally the diagnosis of carcinocarcoma (Malignant Mixed Mullerian Tumour) was favoured.

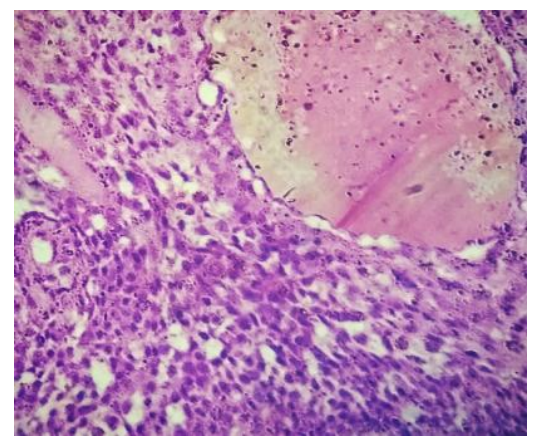

Figure 1: Photomicrograph showing cystic epithelial component with attenuated lining (H\&E;400X)

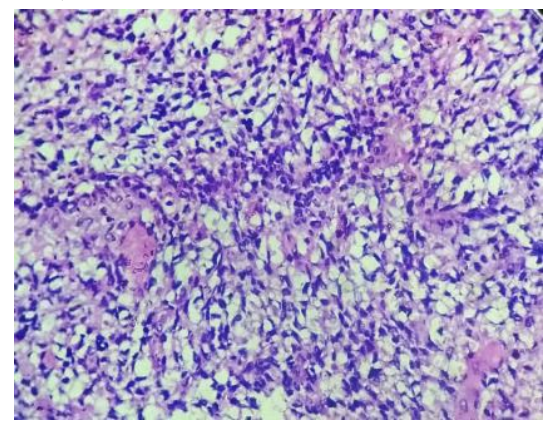

Figure 2: Photomicrograph showing high grade sarcomatous areas (H\&E; 400X)

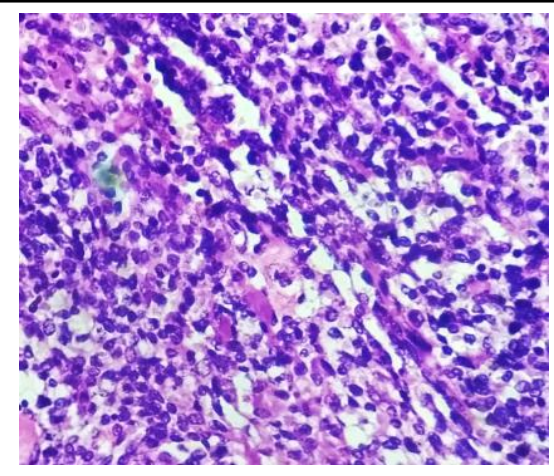

Figure 3: Photomicrograph showing poorly differentiated epithelial components (H\&E;400X)

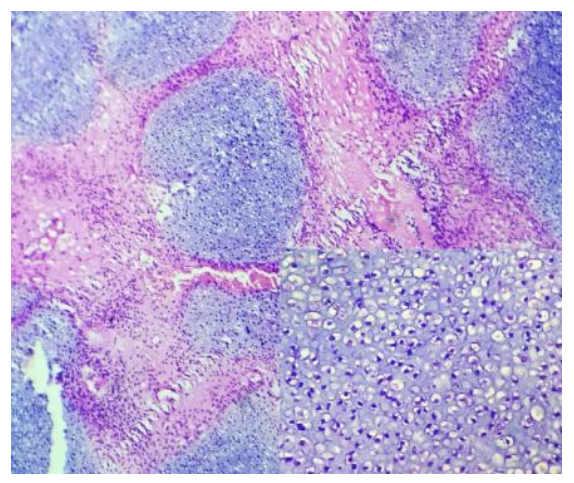

Figure 4: Photomicrograph showing areas of cartilaginous differentiation (H\&E; 100X)[ InsetImmature cartilage;400X]

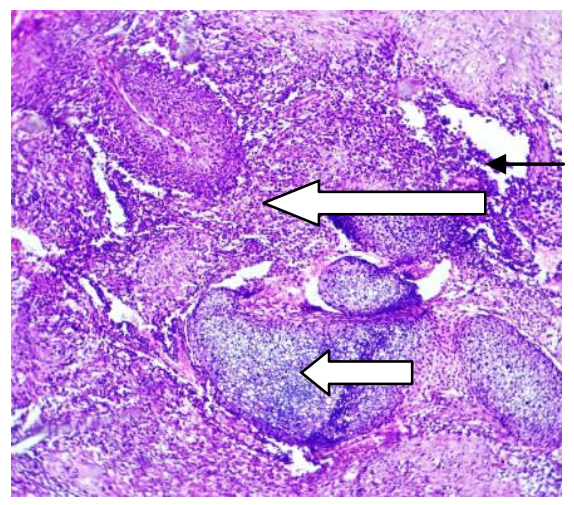

Figure 5: Photomicrograph showing malignant epithelial component (thin arrow) and mesenchymal components(thick arrow) with immature chondromatous element(short arrow) (H\&E;100X)

\section{Discussion}

Malignant neoplasm of uterus containing both carcinomatous and sarcomatous elements are designated in the World Health Organisation (WHO) classification as carcinosarcomas. In 1899, Gebhardt appears to have reported the first 
case; Meyer, after a personal examination of the slides, accepted it as authentic ${ }^{[5]}$.

Carcinosarcomas representing less than $5 \%$ of all uterine tumors, account for $16.4 \%$ of all deaths caused by a uterine malignancy ${ }^{[6]}$.

There is typically an intimate admixture of high grade malignant neoplasm of epithelium and mesenchyme; one or the other may predominate. The two components are usually distinct and sharply demarcated but merging can be obsrerved. The epithelium is most often of endometrioid or serous types but other Mullerian types may be encountered. The mesenchymal component, is, for the most part, a high grade, non-specific sarcoma, but heterologous elements including rhabdomyosarcoma, chondrosarcoma and rarely, osteosarcoma are seen in $50 \%$ of cases ${ }^{[7]}$.(WHO 2016)

Immunohistochemical studies and cytogenetics analysis established that both tumoral elements derive from a common stem cell ${ }^{[8,9]}$. Owing to financial constraints, IHC could not be done in our case.

It is a tumor predominantly identified at the postmenopausal woman, but it can also be found at young women or children ${ }^{[10]}$.

The clinical manifestations are non-specific common to other neoplasias with the same localization. Clinically, uterine bleeding, an enlarged uterus, pain and abdominal distension characterize them. They are frequently localized at the level of the posterior wall of the uterine body in the fundus region. Macroscopically, it has a polypoid appearance and of soft consistency, variable color with areas of necrosis and hemorrhage ${ }^{[11]}$.

Histopathology remains the gold standard for diagnosis but ancilliary techniques like immunehistochemistry can be tried. Immunohistochemically carcinosarcomas express epithelial markers like Epithelial Membrane Antigen (EMA), pancytokeratin and stromal lineage markers like desmin or S100 ${ }^{[12]}$.

These tumours are associated with a poor outcome and have a pattern of spread similar to high grade endometrial carcinoma. A high proportion of patients with apparently clinically stage I disease have evidence of extra uterine spread at the time of diagnosis. Metastatic spread is typically to pelvic and para-aortic lymph nodes, sometimes with distant haematogenous metastases to lung, brain and bone. However most of the patients die as a consequence of local pelvic/abdominal recurences. The presence of heterologous elements is a statistically significant poor prognostic factor in stage I disease ${ }^{[13]}$ (WHO2016).

While hysterectomy with bilateral salpingooophorectomy remains the mainstay of treatment. Recurrences occur in over half of patients after surgical treatment; high rates of recurrences and metastasis suggest a need for lymphadenectomy and post operative adjuvant treatment ${ }^{[14]}$.

\section{References}

1. Hubalek M, Ramoni A, Mueller-Holzner E, Marth C. Malignant mixed mesodermal tumor after tamoxifen therapy for breast cancer. Gynecol Oncol. 2004;95:264-266. [PubMed]

2. Grigoriadis C, Androutsopoulos G, Zygouris D, Arnogiannaki N, Terzakis E. Uterine malignant mixed Mullerian tumor after adjuvant tamoxifen treatment for breast cancer. Eur J Gynaecol Oncol. 2013;34:94-98. [PubMed]

3. Sebenik M, Yan Z, Khalbuss WE and Mittal Ket al: Malignant mixed mullerian tumor of the vagina: Case report with review of the literature, immunohisto-chemical study and evaluation for human papilloma virus. Hum Pathol 38: 1282-1288, 2007.

4. sternberg's Diagnostic Surgical Pathology, $6^{\text {th }}$ edition,vol II ,2494

5. Meyer, R.: in Veit-Stoeckel et al : 770774, 1930.

6. J. S. Bosquet, S. A. Terstriep, W. A. Cliby et al: The impact of multi-modal therapy on survival for uterine carcinosarcomas, Gynecologic Oncology, vol. 116, no. 3, pp. 419-423, 2010. 
7. Ostor AG, Rollason TP (2003).Mixed tumours of the uterus. In:Haines \&Taylor Obstetrical and Gynaecological Pathology. Fox H, Wells M,eds. Churchill Livingstone: 549-584.

8. Emoto M., Iwasaki H., Kikuchi M., Ishiguro M.Kubota T., Izumi H., Shirakawa K., Kaneko Y., Two cell lines established from mixed müllerian tumors of the uterus. Morphologic, immunocytochemical, and cytogenetic analyses, Cancer, 1992, 69(7):1759-1768

9. Gorai I., Yanagibashi T., Taki A., Udagawa K., Miyagi E., NakazawaT., Hirahara F., Nagashima Y., Minaguchi H., Uterine carcinosarcoma is derived from a single stem cell: an in vitro study, Int $\mathbf{J}$ Cancer, 1997, 72(5):821-827.

10. Amr S. S., Tavassolif. A., Hassan A. A., Issa A. A., Madanat F. F., Mixed mesodermal tumor of the uterus in a 4year-old girl, 1986, Int J Gynecol Pathol, 5(4):371-378.

11. Silverberg S. G.,Major F. J., Blessing J. A., Fetter B., Askin F. B., Liao S. Y., Miller A., Carcinosarcoma (malignant mixed mesodermal tumor) of the uterus. A Gynecologic Oncology Group pathologic study of 203 cases, Int J Gynecol Pathol, 1990, 9(1):1-19.

12. Kanthan R, Senger JL Uterine carcinosarcomas (malignant mixed müllerian tumours): a review with special emphasis on the controversies in management. Obstet Gynecol Int. 2011; 2011:470795.

13. Ferguson SE, Tomos C, Hummer A, Barakat RR, Soslow RA(2007).Prognostic features of surgical stage I uterine carcinosarcoma. Am J Surg Pathol 31:1653-1661.

14. S. A. El-Nashar and A. Mariani, -Uterine carcinosarcoma,\| Clinical Obstetrics and Gynecology, vol. 54, 2, pp. 292-304, 2011. 